\title{
Kinetics of Electron Exchange between Bromopyrogallol Red and Periodate Ion in Aqueous Acidic Medium
}

\author{
${ }^{*}$ S. O. Idris ${ }^{1}$, G.B Adeyemo ${ }^{1}$, J. F. Iyun ${ }^{1}$, B. Myek ${ }^{2}$ \\ ${ }^{1}$ Department of Chemistry, Ahmadu Bello University, Zaria, Nigeria \\ ${ }^{2}$ Department of Basic Research, National Research Institute for Chemical Technology, Zaria, Nigeria \\ *Corresponding author e-mail: alhajisoidris@yahoo.com
}

\section{ABSTRACT}

The kinetics of the electron transfer reaction between Bromopyrogallol $\left(\mathrm{BPRH}_{2}\right)$ and periodate ion in aqueous acidic solution has been studied in the acid range $0.1 \times 10^{-4} \leq\left[\mathrm{H}^{+}\right] \leq 2 \times 10^{-4} \mathrm{~mol} \mathrm{dm}^{-3}$, ionic strength, I, range $0.01 \leq[\mathrm{I}] \leq 0.18$ $\mathrm{mol} \mathrm{dm}^{-3}(\mathrm{NaCl})$ and $\mathrm{T}=29 \pm 1 .{ }^{\circ} \mathrm{C}$. The reaction shows a first order dependence on [reductant] and [oxidant] with an overall second order at constant $\left[\mathrm{H}^{+}\right]$. It also displayed an inverse dependence on the acid concentration of the reaction medium. The reaction, therefore, conforms to the rate law:

$-\mathrm{d}\left[\mathrm{BPRH} \mathrm{H}_{2}\right] / \mathrm{dt}=\mathrm{Kk}_{3}\left[\mathrm{BPRH}_{2}\right]\left[\mathrm{IO}_{4}\right]\left[\mathrm{H}^{+}\right]^{-2}$

The stoichiometry of the reaction is $1: 1$. Added anions had no effect on the rate of the reaction. Spectroscopic investigation indicates that an intermediate complex is probably formed in the course of this reaction. The reaction is believed to proceed via the innersphere mechanistic pathway.

Key words: Kinetics, Periodate, Mechanism, Bromopyrogallol red.

\section{Council for Innovative Research}

Peer Review Research Publishing System

Journal of Advances in Natural Sciences

Vol. 2, No. 2

editorjansonline@gmail.com

www.cirworld.com 


\subsection{INTRODUCTION}

Interest in periodate ion as an oxidant in electron transfer reactions has received some attention [1, 23,4$]$. It has been found that it oxidises both labile complexes and inert complexes readily, possessing at least one bridging ligand. Oxidations of inorganic substrates by periodate ion are reported to proceed through the innersphere mechanism [5]. The kinetics and mechanism of oxidation of chromium(III)-tetraoxalurea complex by periodate ion was also reported [6]. It is proposed that electron transfer proceeds through an innersphere mechanism through coordination of the $\mathrm{IO}_{4}{ }^{-}$to chromium(III).

Bromopyrogallol red, a dye, here and thereafter referred to as $\mathrm{BPRH}_{2}$ for convenience, is of immense importance because of a wide range of its uses as a metal indicator for the chelatometric titration of $\mathrm{Bi}, \mathrm{Co}(\mathrm{II}), \mathrm{Ni}$ and $\mathrm{Pb}$ as photometric reagents for various heavy metals and for indirect determination of anion such as halides and cyanides [7].

In spite of these and other numerous uses, literature on its redox chemistry is scanty. This is our attraction for embarking on the investigation. In this study, we present the kinetics of electron exchange between bromopyrogallol red and periodate ion in aqueous acidic medium with a view to gain insight into the mechanistic pathway of redox chemistry of the dye.

\subsection{Materials and Methods}

The chemicals used were of analytical grade and were used without further purification. Standard solution of bromopyrogallol red was prepared by dissolving accurate weight of bromopyrogallol red dye in a known volume of distilled water. Sodium periodate solution was prepared by dissolving known quantities in known volume of distilled water. All other reagents used were of analytical grade.

The stoichiometry of the reaction was determined spectrophotometrically using the mole ratio method by keeping the concentration of the dye constant at $2.0 \times 10^{-5} \mathrm{~mol} \mathrm{dm}^{-3},\left[\mathrm{H}^{+}\right]=1.0 \times 10^{-2} \mathrm{~mol} \mathrm{dm}^{-3}, \mathrm{I}=0.1 \mathrm{~mol} \mathrm{dm}^{-3}, \lambda_{\max }=410 \mathrm{~nm}, \mathrm{~T}=$ $29.5 \pm 0.5^{\circ} \mathrm{C}$ and $\left[\mathrm{IO}_{4}^{-}\right]=5.0 \times 10^{-6}-1.0 \times 10^{-4} \mathrm{~mol} \mathrm{dm}^{-3}$. The stoichiometry was evaluated from the plot of absorbance versus [reductant]/ [oxidant] after the reaction had gone to completion by the observation of a steady zero absorbance value over a period of two days.

A Corning Colorimeter Model 252 spectrophotometer was used to follow decrease in absorbance of the dye at $410 \mathrm{~nm}$. The kinetic runs were conducted under pseudo - first order conditions with [ $\left.\mathrm{IO}_{4}\right]$ ] in at least 100 - fold excess over bromopyrogallol red. Temperature, ionic strength and hydrogen ion concentration were maintained constant as $T=29.5 \pm$ $0.1^{\circ} \mathrm{C}, \mathrm{I}=0.5 \mathrm{~mol} \mathrm{dm}^{-3}(\mathrm{NaCl})$ and $\left[\mathrm{H}^{+}\right]=1.0 \times 10^{-2} \mathrm{~mol} \mathrm{dm}^{-3}(\mathrm{HCl})$. The pseudo-first order plots of log $\left(\mathrm{A}_{t}-\mathrm{A}_{\infty}\right)$ versus time were made (where $A_{t}$ and $A_{\infty}$ are the absorbance at time $t$ and at the end of the reaction respectively). From the slope of the plots, the pseudo-first order rate constants $\left(k_{1}\right)$ were determined [8].

The effect of hydrogen ion concentration on the rate of reaction was investigated by varying $\left[\mathrm{H}^{+}\right]$in the range $0.01 \leq$ $\left[\mathrm{H}^{+}\right] \leq 0.07 \mathrm{~mol} \mathrm{dm}^{-3}$, while $\left[\mathrm{BPRH}_{2}\right]$ and $\left[\mathrm{IO}_{4}{ }^{-}\right]$were kept constant at $29.5 \pm 0.5^{\circ} \mathrm{C}$ and $\mathrm{I}=0.1 \mathrm{~mol} \mathrm{dm}^{-3}(\mathrm{NaCl})$. The effect of ionic strength on the rate of the reaction was studied in the range $0.05 \leq[\mathrm{l}] \leq 0.7 \mathrm{~mol} \mathrm{dm}^{-3}$ (NaCl) while the concentration of $\left[\mathrm{H}^{+}\right]$and $\left[\mathrm{IO}_{4}{ }^{-}\right]$were kept constant at $29.5 \pm 0.5^{\circ} \mathrm{C}$. The effect of added cations and anions were investigated by keeping the concentration of other reactants constant while varying the cations and anions concentrations as follows $[\mathrm{Z}]=\left(10 \times 10^{-3}-100 \times 10^{-3}\right) \mathrm{mol} \mathrm{dm}^{-3}$ and $[\mathrm{X}]=\left(10 \times 10^{-3}-100 \times 10^{-3}\right) \mathrm{mol} \mathrm{dm}^{-3}\left(\right.$ where $\mathrm{Z}=\mathrm{Ca}^{2+} ; \mathrm{K}^{+}$and X $=$ $\mathrm{SO}_{4}^{2-}$ and $\mathrm{NO}_{3}^{-}$)

\subsection{Results and Discussion}

The result of stoichiometric studies for the reaction shows that one mole of $\mathrm{BPRH}_{2}$ consumed one mole of periodate ion. Hence the overall equation for the reaction is as shown in equation (1).

$\mathrm{BPRH}_{2}+\mathrm{IO}_{4}^{-} \longrightarrow$ product

However, the stoichiometry of $2: 1$ has been reported for the reduction of $\mathrm{IO}_{4}{ }^{-}$by indigo carmine [9] and naphthol green $\mathrm{B}$ [10] in aqueous acidic medium.

Pseudo-first order plots of log $\left(A_{t}-A_{\infty}\right)$ versus time were linear to more than $80 \%$ extent of the reaction. Such linearity suggests that the reaction is first order with respect to bromopyrogallol red. The order of the reaction with respect to $\left[\mathrm{IO}_{4}{ }^{-}\right]$was also determined by plotting log $\mathrm{k}_{1}$ against log $\left[\mathrm{IO}_{4}{ }^{-}\right]$. A slope of about unity was obtained which indicates that the order of reaction with respect to $\left[\mathrm{IO}_{4}^{-}\right]$is one. Therefore, the reaction has a second order overall at constant $\mathrm{H}^{+}$

Effect of changes in ionic strength of the reaction medium indicated that the rate constant increases with increase in ionic strength (Table 1). This conforms with positive Bronsted Debye salt effect, implying that the activated complex is composed of reactants of same charge sign. Similar result has been reported on the oxidation of naphthol green B by periodate ion [10]. A plot of log $k_{2}$ versus $I^{1 / 2}$ gave a slope of 0.449 (Fig.1). The non-integral value suggests that there might be other interactions within the reaction medium.

The result in Table 1 shows that the rate of reaction decreases with increase in $\left[\mathrm{H}^{+}\right]$in the range $0.01 \leq\left[\mathrm{H}^{+}\right] \leq 0.07$ $\mathrm{mol} \mathrm{dm}{ }^{-3}$. Reaction of this nature suggests an inverse acid dependence. Similar result has been reported in earlier studies of the oxidant [4]. A slope of 2 was obtained when a plot of $\operatorname{logk}_{1}$ versus $\log \left[\mathrm{H}^{+}\right]$was made, indicating release of two protons prior to or during electron transfer process. Added cations and anions had no effect on the rate of the reaction (Tables 2 and 3). The lack of dependence of these ions shows that the co-ordination centre of the reactants is linked in the activated complex, which is a characteristic of reaction proceeding by the innersphere mechanism . This view is further 
reinforced by the intercept obtained in the Michaelis - Mentens plot of $1 / \mathrm{k}_{1}$ versus $1 / \mathrm{IO}_{4}^{-}$(Fig. 2). Free radical test did not yield gel formation when acrylamide was added to a partially oxidised mixture in excess methanol.

\section{Reaction Mechanisms}

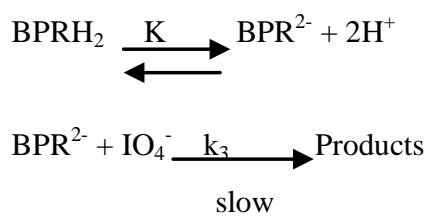

Rate $=\mathrm{k}_{3}\left[\mathrm{BPRH}_{2}\right]\left[\mathrm{IO}_{4}^{-}\right]$
(4)

Rate $=\mathrm{K} \mathrm{k}_{3}\left[\mathrm{BPRH}_{2}\right]\left[\mathrm{IO}_{4}^{-}\right]\left[\mathrm{H}^{+}\right]^{2-}$

Table 1: Pseudo - first order and second order rate constants for the reaction of Bromopyrogallol red and $\mathrm{IO}_{4}{ }^{-}$at $\left[\mathrm{BPRH}_{2}\right]$ $=2.0 \times 10^{-5} \mathrm{~mol} \mathrm{dm}^{-3}, \lambda=410 \mathrm{~nm}$ and $\mathrm{T}=29.5 \pm 0.5^{\circ} \mathrm{C}$

\begin{tabular}{|c|c|c|c|c|}
\hline $\begin{array}{l}10^{3}\left[1 O_{4}\right] \\
\mathrm{mol} \mathrm{dm}^{-3}\end{array}$ & $\begin{array}{c}10^{2}\left[\mathrm{H}^{+}\right] \\
\mathrm{mol} \mathrm{dm}\end{array}$ & $\begin{array}{l}10^{1}, \mathrm{I} \\
\mathrm{mol} \mathrm{dm}{ }^{-3}\end{array}$ & $\begin{array}{l}10^{3} k_{1} \\
s^{-1}\end{array}$ & $\begin{array}{c}k_{2} \\
\mathrm{dm}^{3} \mathrm{~mol}^{-1} \mathrm{~s}^{-1}\end{array}$ \\
\hline 2.0 & 1.0 & 5.0 & 6.2 & 0.137 \\
\hline 3.0 & 1.0 & 5.0 & 7.4 & 0.135 \\
\hline 4.0 & 1.0 & 5.0 & 8.8 & 0.140 \\
\hline 5.0 & 1.0 & 5.0 & 9.2 & 0.130 \\
\hline 6.0 & 1.0 & 5.0 & 9.2 & 0.120 \\
\hline 7.0 & 1.0 & 5.0 & 1.2 & 0.143 \\
\hline 8.0 & 1.0 & 5.0 & 1.2 & 0.135 \\
\hline 3.0 & 1.0 & 0.5 & 4.4 & 0.079 \\
\hline 3.0 & 1.0 & 1.0 & 5.0 & 0.091 \\
\hline 3.0 & 1.0 & 2.0 & 5.6 & 0.102 \\
\hline 3.0 & 1.0 & 3.0 & 6.2 & 0.112 \\
\hline 3.0 & 1.0 & 4.0 & 6.8 & 0.123 \\
\hline 3.0 & 1.0 & 5.0 & 7.4 & 0.135 \\
\hline 3.0 & 1.0 & 6.0 & 7.8 & 0.141 \\
\hline 3.0 & 1.0 & 7.0 & 8.7 & 0.158 \\
\hline 3.0 & 1.0 & 5.0 & 7.4 & 0.135 \\
\hline 3.0 & 2.0 & 5.0 & 5.2 & 0.095 \\
\hline 3.0 & 3.0 & 5.0 & 4.4 & 0.080 \\
\hline 3.0 & 4.0 & 5.0 & 3.7 & 0.067 \\
\hline 3.0 & 5.0 & 5.0 & 3.4 & 0.062 \\
\hline 3.0 & 6.0 & 5.0 & 3.2 & 0.058 \\
\hline 3.0 & 7.0 & 5.0 & 2.9 & 0.053 \\
\hline
\end{tabular}


Table 2: Rate data for the effect of added cations $\left(\mathrm{Ca}^{2+}\right.$ and $\left.\mathrm{K}^{+}\right)$on the rate of reaction of Bromopyrogallol red with $\mathrm{IO}_{4}{ }^{-}$at $\left[\mathrm{BPRH}_{2}\right]=2.0 \times 10^{-5} \mathrm{~mol} \mathrm{dm}^{-3},\left[\mathrm{IO}_{4}\right]=3.0 \times 10^{-3} \mathrm{~mol} \mathrm{dm}^{-3},\left[\mathrm{H}^{+}\right]=1.0 \times 10^{-2} \mathrm{~mol} \mathrm{dm}^{-3}, \mathrm{I}=0.50 \mathrm{~mol} \mathrm{dm}^{-3}, \lambda=$ $410 \mathrm{~nm}$ and $\mathrm{T}=29.5 \pm 0.5^{\circ} \mathrm{C}$

\begin{tabular}{|c|c|c|c|}
\hline Ion & $\begin{array}{l}10^{3} \text { [ion], } \\
\mathrm{mol} \mathrm{dm}^{-3}\end{array}$ & $\begin{array}{l}10^{3} \mathrm{k}_{1}, \\
\mathrm{~s}^{-1}\end{array}$ & $\begin{array}{c}\mathrm{k}_{2}, \\
\mathrm{dm}^{3} \mathrm{~mol}^{-1} \mathrm{~s}^{-1}\end{array}$ \\
\hline \multirow[t]{7}{*}{$\mathrm{Ca}^{2+}$} & 10.0 & 7.5 & 0.136 \\
\hline & 20.0 & 7.6 & 0.138 \\
\hline & 30.0 & 7.6 & 0.138 \\
\hline & 40.0 & 7.6 & 0.138 \\
\hline & 60.0 & 7.6 & 0.138 \\
\hline & 80.0 & 7.6 & 0.138 \\
\hline & 100.0 & 7.6 & 0.138 \\
\hline \multirow[t]{7}{*}{$\mathrm{K}^{+}$} & 10.0 & 7.5 & 0.136 \\
\hline & 20.0 & & 0.138 \\
\hline & 30.0 & 7.6 & 0.138 \\
\hline & 40.0 & 7.6 & 0.138 \\
\hline & 60.0 & 7.6 & 0.138 \\
\hline & 80.0 & 7.6 & 0.138 \\
\hline & 100.0 & 7.6 & 0.138 \\
\hline
\end{tabular}

Table 3: Rate data for the effect of added anions $\left(\mathrm{SO}_{4}{ }^{2-}\right.$ and $\left.\mathrm{NO}_{3}{ }^{-}\right)$on the rate of reaction of Bromopyrogallol red with $\mathrm{IO}_{4}{ }^{-}$at $\left[\mathrm{BPRH}_{2}\right]=2.0 \times 10^{-5} \mathrm{~mol} \mathrm{dm}^{-3},\left[\mathrm{IO}_{4}^{-}\right]=3.0 \times 10^{-3} \mathrm{~mol} \mathrm{dm}^{-3},\left[\mathrm{H}^{+}\right]=1.0 \times 10^{-2} \mathrm{~mol} \mathrm{dm}^{-3}, \mathrm{I}=0.50 \mathrm{~mol} \mathrm{dm}^{-3}$, $\lambda=410 \mathrm{~nm}$ and $\mathrm{T}=29.5 \pm 0.5^{\circ} \mathrm{C}$

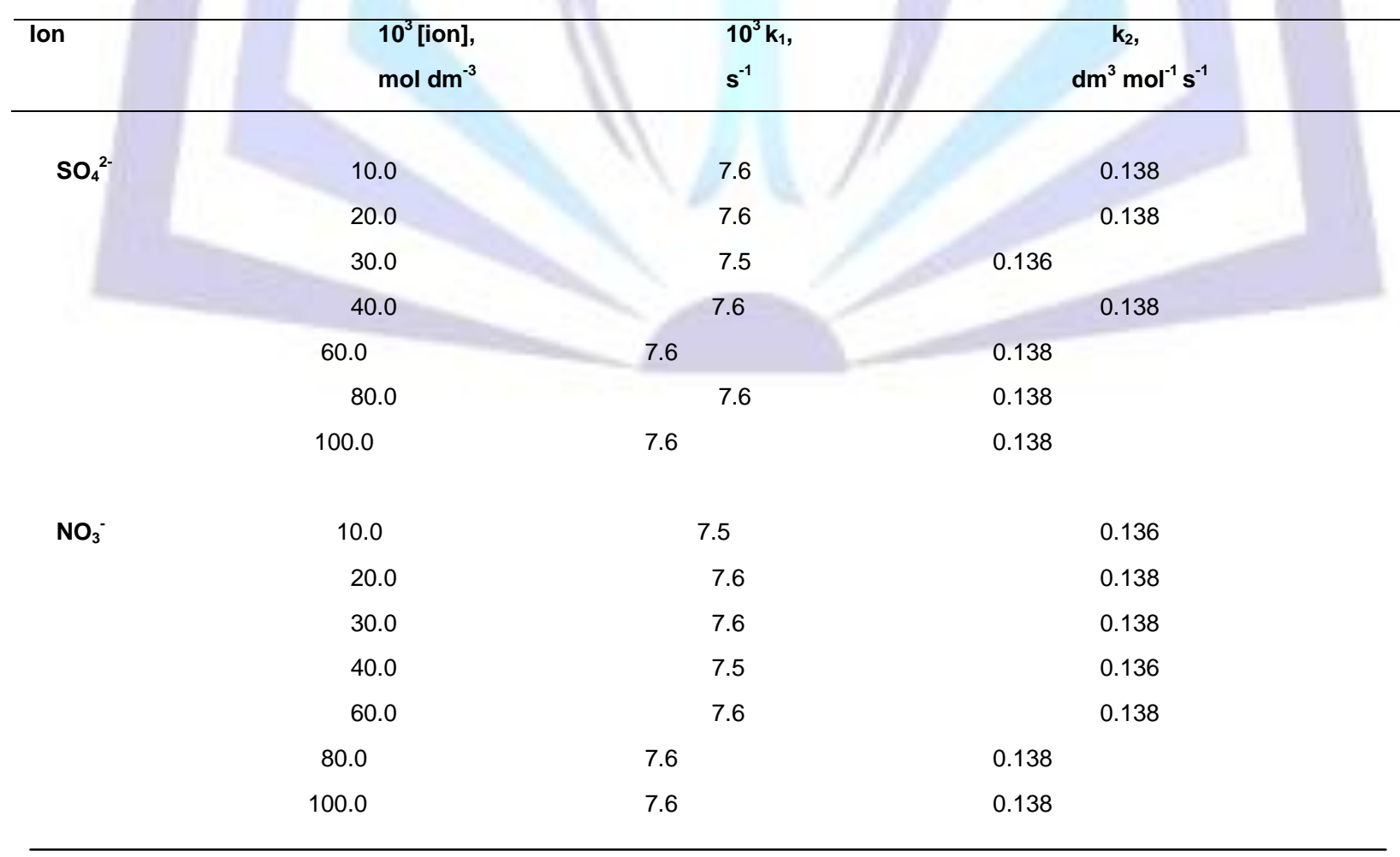




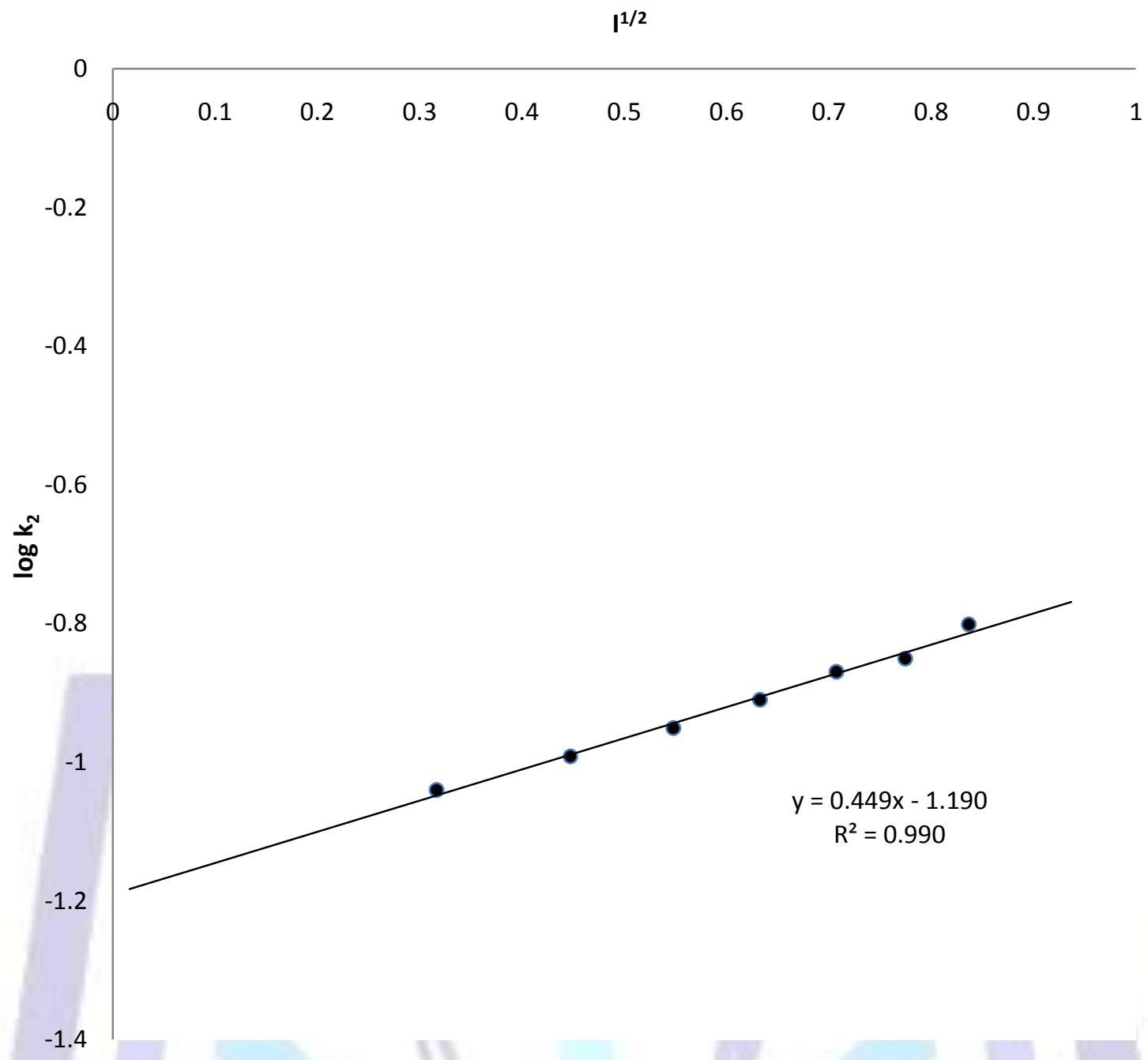

Figure 1: Plot of logk $\mathrm{k}_{2}$ versus $\mathrm{I}^{1 / 2}$ for the redox reaction between Bromopyrogallol and $\mathrm{IO}_{4}{ }^{-}$at

$\left[\mathrm{BPRH}_{2}\right]=2.0 \times 10^{-5} \mathrm{~mol} \mathrm{dm}^{-3},\left[\mathrm{IO}_{4}^{-}\right]=3.0 \times 10^{-3} \mathrm{~mol} \mathrm{dm}^{-3},\left[\mathrm{H}^{+}\right]=1.0 \times 10^{-2} \mathrm{~mol} \mathrm{dm}^{-3}$, $\mathrm{I}=0.05-0.7 \mathrm{~mol} \mathrm{dm}^{-3}, \lambda=410 \mathrm{~nm}$ and $\mathrm{T}=29.5 \pm 0.5^{\circ} \mathrm{C}$ 


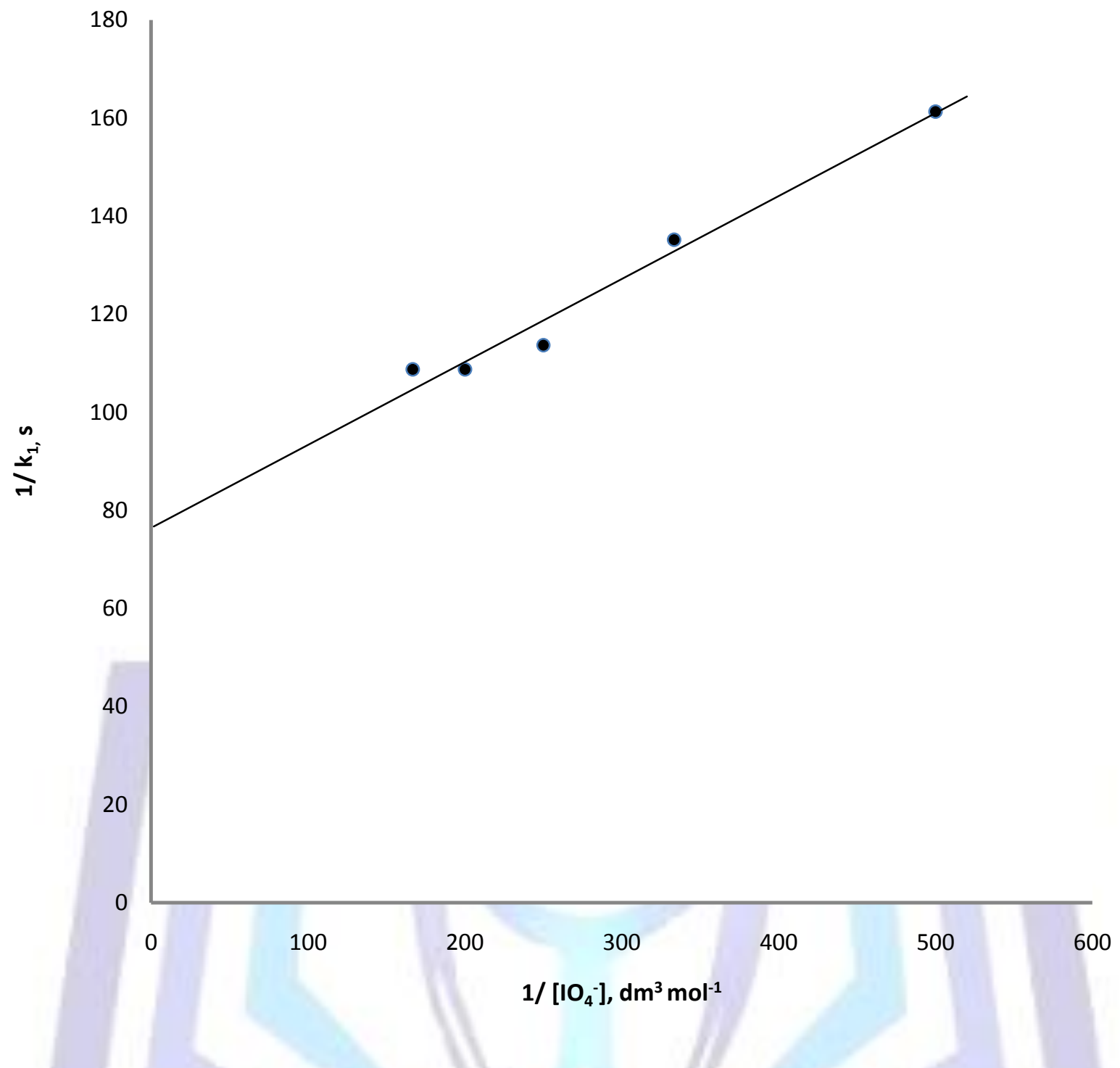

Figure 2: Michaelis - Menten plot for the redox reaction between Bromopyrogallol and $\mathrm{IO}_{4}^{-}$at $\left[\mathrm{BPRH}{ }^{2-}\right]=2.0 \times 10^{-5}$ $\mathrm{mol} \mathrm{dm}{ }^{-3},\left[\mathrm{IO}_{4}{ }^{-}\right]=(2.0-8.0) \times 10^{-3} \mathrm{~mol} \mathrm{dm}^{-3},\left[\mathrm{H}^{+}\right]=1.0 \times 10^{-2} \mathrm{~mol} \mathrm{dm}^{-3}, \mathrm{I}=0.50 \mathrm{~mol} \mathrm{dm}^{-3}, \lambda=410 \mathrm{~nm}$ and $\mathrm{T}=29.5 \pm 0.5^{\circ} \mathrm{C}$

\subsection{CONCLUSION}

The redox reaction of bromopyrogallol red and periodate ion in aqueous acidic medium showed a stoichiometry of $1: 1$, a first order was observed for $\left[\mathrm{BPRH}_{2}\right]$ and $\left[\mathrm{IO}_{4}\right]$ ion with a second order at constant $\mathrm{H}^{+}$. The rate constant increases with increase in ionic strength. Result from the Michaelis - Mentens plot of $1 / \mathrm{k}_{1}$ versus $1 / 1 \mathrm{O}_{4}{ }^{-}$indicates the presence of an intermediate in the rate determining step. Added cations and anions had no effect on the rate of reaction. Based on the above results, it is proposed that the reaction is most probably occurring by the innersphere mechanism.

\section{REFERENCES}

[1] El-Idris, I. F. Mechanistic studies on the reactions of 12-Tungstocobaltate(III) anion in aqueous solution. Unpublished M.Sc.Thesis, Ahmadu Bello University, Zaria Nigeria, 1991.

[2] Abdel-Khalek, A.A., Sayyah, S.M and Abdel-Hamed, F.F. Kinetics and mechanism of oxidation of chromium(III)tetraoxalylurca complex by periodate. Trans. Met. Chem., 1994, 19:108-110.

[3] Ukoha, P.O. Kinetics and mechanism of some redox reactions of - $\mu$-oxobridge iron(III) complex ion and of some oxyanions and thiols. Unpublished Ph.D. thesis. Ahmadu Bello University, Zaria, Nigeria,1999.

[4] Onu, A.D., Iyun, J. F. and Idris, S.O. The kinetics of the reduction of tetraoxoiodate(VII) by n-(2hydroxylethyl)ethylenediaminetriacetatocobaltate (II) ion in aqueous perchloric acid. Trans. Met. Chem., 2009, 34:849853. 
[5] Abdel-Khalek, A.A. and Elsemongy, M.M. Kinetics of the oxidation of

diaqua(nitrilotracetato)-chromium(III) by periodate ion in aqueous solutions. Trans. Met. Chem., 1989, 14, $206-208$.

[6] Abdel-Khalek, A.A., Sayyah, S.M and Abdel-Hamed, F. F. Kinetics and mechanism of oxidation of chromium(III)tetraoxalylurca complex by periodate. Trans. Met. Chem., 1994, 19:108-110.

[7] Keihei, U., Toshiaki, I. and Chang, K. L. Handbook of organic and analytical reagents, $2^{\text {nd }}$ ed. Boca Raton, CRC Press, 1992.

[8] Mohammed, Y., lyun, J. F. and Idris, S. O. Kinetic approach to the mechanism of the redox reaction of malachite green and permanganate ion in aqueous acidic medium. Afr. J. Pure Appl. Chem., 2009, 3: 12, 269.

[9] Edokpayi, J.N., Iyun, J.F., Idris, S.O. The kinetics of oxidation of disodium 3,3'-dioxobi-indoline-2, 2'-ylidene-5, 5' disulphonate by heptaoxodichtomate(VI) ion in aqueous acidic medium. J. Appl .Sci. Res. 2010, 2(5)126 - 134

[10] Myek, B., Idris, S. O. and lyun, J. F. Kinetics of the Oxidation of Naphthol Green B by Periodate Ion in Aqueous Hydrochloric Acid Medium. International Journal of Modern Chemistry, 2013, 5(2):127 - 135. 